\title{
Interrelationship between Iranian L2 Learners' Proficiency, Motivational Self System and Self-Regulated Learning Strategies
}

\section{Masoud Rahimi Domakani}

Associate professor of TEFL at Shahrekord University, Iran; rahimi@lit.sku.ac.ir

\author{
Ali Akbar Jafar Pour \\ Assistant professor of TEFL at Shahrekord University, Iran; aliakbar_jafarpour@yahoo.com \\ Misagh Haji Mohammadi
}

M. A. TEFL student at Shahrekord University, Iran; hajimohammadi88@gmail.com

\section{Doi:10.5901/mjss.2016.v7n3p404}

\section{Abstract}

The main purpose of the present study was to investigate the relationship between $L 2$ motivational self system and selfregulated learning strategies of Iranian L2 lower-intermediate and upper-intermediate learners. To this end, correlation analysis and regression analysis were implemented. The results of the correlation analysis showed that among the components of $L 2$ motivational self system, ideal L2 self and criterion measure were correlated significantly with SRL strategies. Also, attitude and integrativeness showed significant relationships; however, to a lesser degree with SRL strategies. In contrast, ought-to L2 self showed no significant relationship with SRL strategies. It was also confirmed that Iranian L2 learners were highly affected by the visualization of their own desired self than the visualization of their obliged self in their quest of $L 2$ learning. The results of the regression analysis showed that criterion measure was the strongest predictor of SRL strategies. At the second place, the ideal L2 self was the other predictor of SRL strategies. Finally, in order to investigate if there were any differences in the mean scores of L2 motivational self system and SRL strategies between Iranian L2 upper-intermediate and lower-intermediate learners, an independent samples t test was run. The results of the independent samples t test confirmed that Iranian L2 upperintermediate learners with higher level of $L 2$ competence were stronger at their L2 motivational self system: They possessed more intended learning effort, stronger visualization of their ideal L2 selves, and higher levels of attitude and integrativeness. They were also better at implementing different levels of SRL strategies.

Keywords: L2 motivational self system, Self-regulated learning strategies, L2 upper-intermediate learners, L2 lower-intermediate learners

\section{Introduction}

The growing interest on second language (L2) motivation as an unavoidable issue which affects education, especially language learning, has made linguistics and psycholinguistics do a large number of research on L2 motivation during centuries. The first ever studies on L2 motivation were conducted by Gardner and Lambert, in which integrativeness was viewed as the central issue in L2 acquisition and motivation to learn the target language (Gardner \& Lambert, 1959). However, the new role of English as an international language has brought Gardner's model into question. In an attempt to explain the vagueness of integrativeness, Dörnyei and Csizér (2002) concluded that "the process of identification theorized to underpin integrativness might be better explained as an internal process of identification within the person's self-concept, rather than identification within an external reference group" (p. 453). This new view of integrativeness made Dörnyei (2005) to develop a new conceptualization of L2 motivation, namely L2 motivational self system.

L2 motivational self system (Dörnyei, 2010), as a new motivation construct, builds upon the foundation laid by Gardner (1985) and "at the same time, broadens the scope of the theory to make it applicable in diverse language learning environments in our globalized world" (p. 75). In an attempt to synthesize a number of influential new approaches in the field (e.g. Noels, 2003; Ushioda, 2001), this model grew out of a combination of empirical research findings and theoretical considerations (Dörnyei, 2010). The model relates "two future self-guides, associated with imagined experience and a third constituent rooted in actual experience" (Dörnyei, 2014, p. 9). This model comprises three main components: Ideal L2 self, ought-to L2 self, and L2 learning experience. According to Dörnyei and Chan 
(2013), Ideal L2 self, concerning the L2 specific facet of one's ideal self, that is, if we would like to become speakers of an $\mathrm{L} 2$, the ideal $\mathrm{L} 2$ self can be a powerful motivator since we would like to reduce the discrepancy between our actual and ideal selves. The second component, ought-to L2 self, regarding the attributes individuals believe they ought to possess in order to avoid possible negative outcomes. Accordingly, such perceived duties, external expectations, and obligations, which are imposed by external factors such as parents, peers, or environment, may bear little resemblance to the individual's own desires and wishes. Finally, the last complementary component, L2 Learning experience, concerning situation-specific motives related to the immediate learning environment and experience such as the positive impact of success or the enjoyable quality of a language course for an $L 2$ learner.

Related to human psychology, L2 motivational self system can be considered as determiner of one's imagination toward effective learning. Besides, self-regulated learning (SRL), as a matter of individual differences, has been considered to be influential in achieving success in an L2 (Schunk, 2009; Zimmerman, 1986, 1989, 2000; Zimmerman \& schunk, 2001). According to its Latin root, "self-regulation involves not only self-management but also self-righting, i.e., self-adjustment or self-adaptation if something goes off track or needs improvement" (Oxford, 2013, p. 12). SRL or selfregulation refers to processes whereby learners activate and sustain their cognitions, affects, and behaviors that are oriented systematically toward the attainment of their goals (Zimmerman \& Schunk, 2011). Researchers have determined several self-regulatory processes that students would instigate, modify, and sustain. These processes involve "attending to instruction, cognitively processing information, rehearsing and relating new learning to prior learning, believing that one is capable of learning, and establishing productive work and social environments" (Schunk, 2009, p. 1). Characteristics attributed to self-regulated learners concern with those attributed to high-performance and high-capacity students, as opposed to those who show low performance (Zimmerman, 1998, Reyero \& Tourón, 2003, cited in Montalvo \& Toress, 2004); however, with adequate training, all students can promote their control over learning and performance.

SRL strategies are defined as deliberate, goal-directed attempts that manage and control the efforts of selfregulated learners (Afflerbach, Pearson, \& Paris, 2008, cited in Oxford, 2013). "These strategies are broad teachable actions that learners choose from among alternatives and employ for L2 learning purposes (e.g., constructing, internalizing, storing, retrieving, and using information; completing short-term tasks; and/or developing L2 proficiency and self-efficacy in the long term)" (Oxford, 2013, p. 12). Pintrich, Smith, Garcia, and McKeachie (1991) introduce three classifications of SRL strategies: cognitive, metacognitive, and resource management strategies. Cognitive strategies involve learners' use of basic and complex strategies for the processing of information from texts or lectures (Garcia \& Pintrich, 1995). Metacognitive strategies concern learners' knowledge and self-regulation of their own cognition through cognitive learning activities such as planning and monitoring (Pintrich, 1999). Finally, resource management strategies make learners take control of their own learning environment.

This study, by integrating some Iranian learners' L2 motivational self system and their SRL strategies, was an attempt to open new doors for SLA researchers in human psychology domain. Accordingly, the following research questions were formulated:

1. Is there any significant relationship between Iranian learners' L2 motivational self system and their SRL strategies (along with its components)?

2. Which components of $L 2$ motivational self system can be predicted by Iranian L2 learners' SRL strategies?

3. Are there any significant differences in the mean scores of L2 motivational self system and SRL strategies of Iranian L2 upper-intermediated and lower-intermediate learners?

\section{Methodology}

\subsection{Participants}

For the main purpose of this study, a total of 71 Iranian students were selected randomly from Shahrekord University in Iran. Based on their levels of English proficiency, the participants were divided into two levels of upper-intermediate and lower intermediate learners. They were B.A. learners of English and M.A. learners of TEFL, with the mean age of 23.

\subsection{Instruments}

\subsubsection{English Learner Questionnaire}

To determine Iranian leaners' L2 motivational self system, a large-scale attitudinal questionnaire by Taguchi, Magid, and Papi (2009) was employed. The English Learner Questionnaire comprises 76 items. This questionnaire evaluates 
learners on a six-point Likert scale (ranges from strongly agree to strongly disagree) and it takes nearly 30 minutes to be filled out. While the questionnaire contains a large number of items measuring many latent variables, for the main purpose of this study, three main components of L2 motivational self system along with some variables which correlated highly with the main components were employed:

1. Ideal $L 2$ self $(\alpha=.81)$ : Six items concerned with the first key component of $L 2$ motivational self system, that is, L2-specific facet of one's ideal self.

2. Ought-to $L 2$ self ( $\alpha=.68)$ : Six items measured the second component of $L 2$ motivational self system, that is, L2-specific facet of one's ought-to self.

3. Criterion measures ( $\alpha=.78$ ): Six items measured one's intended effort in $\mathrm{L} 2$ learning process.

4. Parental encouragement ( $\alpha=.74)$ : Six items measured the influence of family on one's learning an $L 2$.

5. Attitude toward learning English $(\alpha=.79)$ : Six items concerned with the third complementary facet of $L 2$ motivational self system, that is, one's views toward the English language.

6. Integrativeness ( $\alpha=.60)$ : Three items measured one's desire to integrate into $L 2$ community.

\subsubsection{Motivated Strategies for Learning Questionnaire (MSLQ)}

Subsequently, in order to gather the required data, MSLQ, developed by Pintrich et al. (1991) was employed. As a selfreport instrument, MSLQ comprises 81 items divided into two broad categories: motivation section and learning strategies section. The learners are assessed on a seven-point Likert scale ranging from not at all true of me to very true of me and it takes at least 20-30 minutes to complete the questionnaire. Based on the purpose of this study, the second category which consisted of 50 items and is related to student's use of different cognitive, metacognitive, and resource management strategies was used $(\alpha=.91)$.

\section{Results}

\subsection{Relationship between L2 Motivational Self System and SRL Strategies}

In order to examine the relationship between the learners' L2 motivational self system and their SRL strategies, a Pearson product-moment correlation was estimated. The results of the correlation are shown in table 1:

Table 1. Correlation Analysis of L2 Motivational Self System and SRL Strategies (along with its components)

\begin{tabular}{|l|c|c|c|c|}
\hline L2 motivational self system & SRL strategies & Cognitive strategies & Metacognitive strategies & Resource management strategies \\
\hline Ideal L2 self & $.506^{\star *}$ & $.474^{\star *}$ & $.476^{\star *}$ & $.425^{\star *}$ \\
& .000 & .000 & .000 & .000 \\
\hline Ought-to L2 self & .038 & .018 & .011 & .107 \\
& .756 & .882 & .930 & .375 \\
\hline Criterion measure & $.491^{\star *}$ & $.428^{\star \star}$ & $.415^{\star *}$ & $.482^{\star *}$ \\
& .000 & .000 & .000 & .000 \\
\hline Parental encouragement & .052 & .001 & -.036 & .171 \\
& .668 & .997 & .763 & .153 \\
\hline Attitude & $.282^{\star}$ & $.305^{\star *}$ & $.278^{\star}$ & .187 \\
& .017 & .010 & .019 & .118 \\
\hline Integrativeness & $.282^{\star}$ & $.309^{\star \star}$ & $.285^{\star}$ & .176 \\
& .017 & .009 & .016 & .143 \\
\hline
\end{tabular}

${ }^{\star *}$ Correlation is significant at the 0.01 level (2-tailed)

${ }^{*}$ Correlation is significant at the 0.05 level (2-tailed)

As table 1 depicts, the key component of $L 2$ motivational self system, ideal $L 2$ self, with a correlation of about $(r=.506)$, at 0.01 level of significance, showed the strongest relationship with SRL strategies. In terms of the components of SRL strategies, the ideal L2 self, revealed medium positive correlations: first with metacognitive strategies $(r=.476)$, at 0.01 level of significance, second, with cognitive strategies, $(r=.474)$, at 0.01 level of significance, and third, with resource management strategies $(r=.425)$, at 0.01 level of significance. It indicated that L2 learners with stronger visualization of their ideal selves were stronger in terms of their SRL strategies: They benefited more from metacognitive and cognitive strategies, and to a lesser degree from resource management strategies. 
At the second place, criterion measure, showed a correlation of about ( $r=.491)$, at 0.01 level of significance, with SRL strategies. Regarding SRL strategies components, criterion measure revealed positive medium correlations with resource management strategies $(r=.482)$, at 0.01 level of significance, cognitive strategies $(r=.428)$, at 0.01 level of significance, and metacognitive strategies $(r=.415)$, at 0.01 level of significance. It implied that L2 learners with more intended learning effort were better at their SRL strategies. In contrast to the ideal L2 self, these learners benefited more from resource management strategies than cognitive and metacognitive strategies.

At the third place, the complementary component of L2 motivational self system, attitude, showed small positive correlation with SRL strategies $(r=.282)$, at 0.05 level of significance. Regarding the components of SRL strategies, attitude showed a medium positive correlation with cognitive strategies, in which $(r=.305)$, at 0.01 level of significance, and a small positive correlation with metacognitive strategies, in which $(r=.278)$, at 0.05 level of significance. This variable showed no significant relationship with resource management strategies. It indicated that L2 learners with more positive view toward L2 learning showed more interest in cognitive and metacognitive strategies.

Also, integrativeness, showed a small positive correlation of about $(r=.282)$, at 0.05 level of significance, with SRL strategies. Like attitude, Integrativeness showed a medium positive correlation with cognitive strategies, in which $(r=$ .309), at 0.01 level of significance, and a small positive correlation with metacognitive strategies, in which $(r=.285)$, at 0.05 level of significance. It showed no significant relationship with resource management strategies. This finding implied that L2 learners with more desire to integrate into L2 community were more willing in terms of their cognitive and metacognitive strategies.

Finally, ought-to L2 self showed no significant relationship with SLR strategies (along with its components). Accordingly, no significant relationship was observed between parental encouragement and SRL strategies (along with its components).

\subsection{Predictors of SRL Strategies}

In order to find out the predictors of SRL strategies, a standard multiple regression analysis was run. The summery results for the regression analysis are displayed in table 2 :

Table 2. Standard Multiple Regression of L2 Motivational Self System and SRL Strategies

\begin{tabular}{|l|c|c|c|c|c|}
\hline \multirow{2}{*}{ Model } & \multicolumn{2}{|c|}{ Unstandardized Coefficient } & Standardized Coefficient & \multirow{2}{*}{$T$} & \multirow{2}{*}{ Sig. } \\
\cline { 2 - 5 } & $B$ & Std. Error & Beta & & \\
\hline 1 (Constant) & 2.060 & .577 & & .571 & .001 \\
\hline Ideal L2 self & .286 & .113 & .329 & 2.354 & .014 \\
\hline Ought-to L2 self & -.040 & .133 & -.048 & -.301 & .764 \\
\hline Criterion measures & .281 & .103 & .349 & 2.729 & .008 \\
\hline Parental encouragement & -.039 & .131 & -.049 & -.297 & .767 \\
\hline Attitude & -.072 & .136 & -.081 & -.532 & .596 \\
\hline Integrativeness & .102 & .128 & .117 & .802 & .425 \\
\hline
\end{tabular}

As shown in table 2, the results of the regression analysis revealed that criterion measure, with the largest beta value of $(.349, \mathrm{P}<.05)$, was viewed as the strongest predictor of SRL strategies, meaning that $\mathrm{L} 2$ learners with more intended effort in L2 learning process may benefit more from SRL strategies. At the second place, the ideal L2 self, with the beta value of $(.329, P<.05)$, was the other predictor of SRL strategies, that is, L2 learners with more vivid ideal selves may look for more SRL strategies.

\subsection{Differences in the Mean Scores of L2 Motivational Self System and SRL Strategies between the L2 Upper- intermediate and Lower-intermediate Learners}

In order to examine the differences in the mean scores of $\mathrm{L} 2$ motivational self system and SRL strategies between the $\mathrm{L} 2$ lower-intermediate and upper-intermediate learners, an independent samples $t$ test was run. The results of the independent samples $t$ test are shown in table 3: 
Table 3. Independent Samples $t$ Test of L2 Upper-intermediate versus L2 Lower-intermediate Learners

\begin{tabular}{|c|c|c|c|c|c|c|}
\hline & Levels & $N$ & Mean & $S D$ & $T$ & Sig. \\
\hline \multirow[t]{2}{*}{ Ideal L2 self } & Upper-intermediate & 36 & 5.305 & .591 & \multirow{2}{*}{-4.232} & \multirow[b]{2}{*}{.000} \\
\hline & \begin{tabular}{|l|} 
Lower-intermediate \\
\end{tabular} & 35 & 4.415 & 1.099 & & \\
\hline \multirow[t]{2}{*}{ Ought-to L2 self } & Upper-intermediate & 36 & 2.912 & 1.016 & \multirow{2}{*}{.312} & \multirow{2}{*}{.756} \\
\hline & Lower-intermediate & 35 & 2.988 & 1.050 & & \\
\hline \multirow[t]{2}{*}{ Criterion measure } & Upper-intermediate & 36 & 4.814 & .856 & \multirow{2}{*}{-4.380} & \multirow{2}{*}{.000} \\
\hline & Lower-intermediate & 35 & 3.833 & 1.026 & & \\
\hline \multirow[t]{2}{*}{ Parental encouragement } & Upper-intermediate & 36 & 3.00 & 1.097 & \multirow{2}{*}{.561} & \multirow{2}{*}{.577} \\
\hline & Lower-intermediate & 35 & 3.142 & 1.047 & & \\
\hline \multirow[t]{2}{*}{ Attitude } & Upper-intermediate & 36 & 5.340 & .753 & \multirow{2}{*}{-3.025} & \multirow{2}{*}{.004} \\
\hline & Lower-intermediate & 35 & 4.685 & 1.042 & & \\
\hline \multirow[t]{2}{*}{ Integrativeness } & Upper-intermediate & 36 & 5.175 & .798 & \multirow{2}{*}{-2.773} & \multirow{2}{*}{.007} \\
\hline & Lower-intermediate & 35 & 4.561 & 1.053 & & \\
\hline \multirow[t]{2}{*}{ Cognitive Strategies } & Upper-intermediate & 36 & 5.576 & .486 & \multirow{2}{*}{-13.477} & \multirow{2}{*}{.000} \\
\hline & Lower-intermediate & 35 & 3.702 & .672 & & \\
\hline \multirow[t]{2}{*}{ Metacognitive Strategies } & Upper-intermediate & 36 & 5.326 & .529 & \multirow{2}{*}{-12.240} & \multirow{2}{*}{.000} \\
\hline & Lower-intermediate & 35 & 3.862 & .476 & & \\
\hline \multirow[t]{2}{*}{ Resource management Strategies } & Upper-intermediate & 36 & 4.979 & .526 & \multirow{2}{*}{-9.672} & \multirow{2}{*}{.000} \\
\hline & Lower-intermediate & 35 & 3.713 & .575 & & \\
\hline
\end{tabular}

As table 3 depicts, the results of the independent samples $t$ test showed that there were significant differences in the mean scores of $\mathrm{L} 2$ motivational self system (i.e., criterion measure, ideal L2 self, attitude, and integrativeness) as well as SRL strategies components between the L2 upper-intermediate and lower-intermediate learners. As for the components of $L 2$ motivational self system, Iranian $L 2$ upper-intermediate learners exhibited stronger criterion measure $(t=-4.380, p<$ $0.05)$, ideal L2 self $(t=-4.232, p<0.05)$, attitude $(t=-3.025, p<0.05)$, and integrativeness $(t=-2.773, p<0.05)$ than L2 lower-intermediate learners. Also, Iranian L2 upper-intermediate learners performed differently regarding different levels of SRL strategies in comparison with L2 lower intermediate learners: cognitive strategies $(t=-13.477, p<0.05)$, metacognitive strategies $(t=-12.240, p<0.05)$, and resource management strategies $(t=-9.672, p<0.05)$.

\section{Discussion}

The main purpose of the present study was to investigate the relationship between Iranian English learners' L2 motivational self system and their SRL strategies. The results of the Pearson-product moment correlation coefficient showed that among the components of L2 motivational self system, ideal L2 self and criterion measure correlated highly with SRL strategies. Also, the other components, attitude and integrativeness showed significant relationships; however, to a lesser degree, with SRL strategies. As it has been confirmed, criterion measure, attitude, and integrativeness correlate highly with the ideal L2 self, that is, L2 learners who make more intended efforts toward L2 learning, show more positive desire in L2, and possess more integration toward L2 community have stronger actualized image of their ideal selves (Taguchi et al., 2009; Dornyei \& Csizér, 2002). This positive image of L2 learners' learning process affects their proper use of SRL strategies. In this regard, the result of the study parallels that of Al-Shehri (2009); Csizér and Kormos (2008, 2009); Taguchi et al. (2009). They showed that the ideal L2 self had a positive influence on language learning motivation, the factor that can exert SRL in L2 learning process. Also, the result of this study parallels that of Kormos and Csizér (2014), in which they investigated the relationship between motivational variables, self-regulatory strategies, and autonomous learning. They found that the ideal $\mathrm{L} 2$ self had a strong direct relationship with motivated behavior, which in turn exerted a powerful effect on self-regulatory strategies. They also concluded that positive self-related beliefs are prerequisite for the use of self-regulatory strategies.

In terms of the ought-to L2 self, the result of the study showed that this variable had no significant impact on SRL strategies, meaning that L2 learners' obliged self-image affected by external factors such as obligations from parents or peers had no impact on the use of SRL strategies. In this vein, the result of the study is in line with that of Kim and Kim (2014), in which they found that the ideal L2 self had greater impact on SRL skills than the ought-to L2 self.

Regarding the predictors of SRL strategies, the results of the regression analysis showed that criterion measure was the strongest predictor of SRL strategies. At the second place, the ideal L2 self was observed as the other predictor of SRL strategies. It can be indicated that L2 learners with more intended effort in L2 learning process as well as more 
positive visualization of their ideal selves may seek for more SRL strategies. In this regard, the result of the study parallels that of Zimmerman and Schunk (2008) who confirmed that L2 learners with higher motivated behavior benefit more from SRL strategies.

Finally, the results of the independent samples $t$ test indicated that Iranian L2 upper-intermediate learners performed differently regarding their L2 motivational self system and their SRL strategies levels in comparison with Iranian L2 lower-intermediate learners. In this vein, the result of the study is in line with that of Far, Rajab, and Etemadzdeh (2012) who showed that Iranian L2 final-year learners tend to attribute their efforts to learn an L2 to their idealized self-image in comparison with first-year learners. In this regard, Carlson (1965) concluded that in adolescence, self-image undergoes substantial changes, and therefore, their ideal L2 self is also under transformation (cited in Kormos \& Csizér, 2008). In the present study, the higher difference in L2 motivational self system of Iranian L2 upper-intermediate learners indicated that these learners with higher level of L2 competence and more awareness of the importance of using English in future were stronger in terms of their intended learning effort, their visualization of their ideal L2 self, their attitude toward L2 learning, and their integration into L2 community. Compared to L2 lower-intermediate learners, L2 upper-intermediate learners were more affected by their motivated behavior and internal desires and wishes to learn an L2 than external factors such as family influence and peers. Accordingly, as the ideal L2 self is confirmed to be the stronger predictor of SRL strategies (Kim \& Kim, 2014), Iranian L2 upper-intermediate learners with stronger ideal selves were better at implementing different levels of SRL strategies.

\section{Conclusion, Implications, and Limitations}

As shown in the present study that there are high correlations between L2 motivational self system (ideal L2 self, criterion measure, attitude, and integrativeness) and SRL strategies, the likely conclusion is that in the context of Iran, English learners are more affected by their motivated behavior, their idealized self-image, as well as their desire to integrate into L2 community, which in turns triggers their proper use of SRL strategies. In contrast, ought-to L2 self showed no significant relationship with Iranian L2 learners' SRL strategies, that is, Iranian L2 learners' visualization of a self-image affected by their parents, peers, or environment may have no influential effect on their use of SRL strategies. Also, the result of the study showed that criterion measure and ideal L2 self were the strongest predictors of SRL strategies, that is, Iranian L2 learners with more intended effort and more actualized ideal selves are more motivated in their process of L2 learning, which in turns would trigger more SRL strategies. Finally, the results of the independent samples $t$ test confirmed that Iranian L2 learners with higher level of L2 proficiency would take more advantage of their L2 motivational self system and their SRL strategies.

The findings of the present study reveal some important pedagogical facts, namely that the learners' motivated behavior and positive future self-guide (i.e., ideal L2 self) along with effective SRL strategies can assist and boost up learners in their L2 learning achievements. Thus, the implication for $\mathrm{L} 2$ teachers can be formulated in this message that they should not only take the chances to motivate the learners but also to activate their ideal L2 selves. This can be simply done by providing more interesting and challenging contents as well as devising activities to enhance learners' imaginary skills, which in turns help internalize more vivid and positive ideal L2 self, as an influential inner power that can trigger the effective use of SRL strategies.

Although the present study was an attempt to provide new information and findings in the world of human psychology, it was not far from some limitations. One of its limitations is that it could also be done qualitatively since L2 motivational self system and SRL strategies with mixed method approach can give us more accurate pictures of these psychological domains. Also, the other limitation can arise from the limited sample of the participants. The fact is that if the study included a higher number of participants it could be more outspoken in the generalization of the results. Taking all these limitations into account and seeing the importance of these psychological notions in L2 pedagogy, further research seems to be indispensable.

\section{References}

Al-Shehri, A. S. (2009). Motivation and vision: The relation between the ideal L2 self, imagination, and visual style. In Z. Dörnyei, \& E. Ushioda (Eds.), Motivation, language identity and the L2 self (pp. 164-171). Clevedon: Multilingual Matters.

Csizér, K., \& Kormos, J. (2009). Learning experiences, selves, and motivated learning behavior: A comparative analysis of structural models for Hungarian secondary and university learners of English. In Z. Dörnyei, \& E. Ushioda (Eds.), Motivation, language identity and the L2 self (pp. 98-119). Clevedon: Multilingual Matters.

Csizér, K., \& Kormos, J. (2014). The ideal L2 self, self-regulatory strategies, and autonomous learning: A comparison of different groups of English language learners. In K. Csizér, \& M. Magid (Eds.), The impact of self-concept on language learning (pp. 73-87). 
Bristol: Multilingual Matters.

Dörnyei, Z. (2005). The psychology of the language learner: Individual differences in second language acquisition. Mahwah, NJ: Lawrence Erlbaum Associates.

Dörnyei, Z. (2009). The L2 motivational self system. In Z. Dörnyei, \& E. Ushioda (Eds.), Motivation, language identity and the L2 self (pp. 9-42). Bristol: Multilingual Matters.

Dörnyei, Z. (2010). Researching motivation: From integrativeness to the ideal L2 self. In S. Hunston, \& D. Oakey (Eds.), Introducing applied linguistics: Concepts and skills (pp. 74-83). London: Routledge.

Dörnyei, Z. (2014). Future self-guides and vision. In K. Csizér, \& M. Magid (Eds.), The impact of self-concept on language learning (pp. 7-18). Bristol: Multilingual Matters.

Dörnyei, Z., \& Chan, L. (2013). Motivation and vision: An analysis of future L2 self-images, sensory styles, and imagery capacity across two target languages. Language Learning, 63(3), 437-462.

Dörnyei, Z., \& Csizér, K. (2002). Some dynamics of language attitudes and motivation: Results of a longitudinal nationwide survey. Applied Linguistics, 23(4), 421-462.

Far, H. R., Rajab, A. B., \& Etemadzadeh, A. (2012). Examining the relationship between L2 motivational self system and L2 learning among TESL students. US-China Foreign Language, 10(6), 1266-1270.

Gardner, R. C., \& Lambert, W. E. (1959). Motivational variables in secondlanguage acquisition.Canadian Journal of Psychology/Revue Canadienne de Psyychologie, 13(4), 266.

Gardner, R. C. (1985). Social psychology and second language learning: The role of attitudes and motivation. London: Edward Arnold.

Garcia, T., \& Pintrich, P. R. (1995). Assessing students' motivation and learning strategies: The motivated strategies for learning questionnaire. The annual meeting of the American Educational Research Association. CA: San Francisco.

Kim, T. Y. (2009). The dynamics of L2 self and L2 learning motivation: A qualitative case study of Korean ESL students. English Teaching, 64(3), 49-70.

Kim, T. Y., \& Kim Y. K. (2014). EFL students' L2 motivational self system and self-regulation; Focusing on elementary and junior high school students in Korea. In K. Csizér, \& M. Magid (Eds.), The impact of self-concept on language learning (pp. 87-108). Bristol: Multilingual Matters.

Kormos, J., \& Csizér, K. (2008). Age-related differences in the motivation of learning English as a foreign language: Attitudes, selves, and motivated learning behavior. Language Learning, 58(2), 327-355.

Kormos, J., Kiddle, T., \& Csizer, K. (2011). System of goals, attitudes, and self-related beliefs in second-language-learning motivation. Applied Linguistics, 32(5), 495-516.

Montalvo, F. T., \& Torres, M. C. G. (2004). Self-regulated learning: Current and future directions. Electronic Journal of Research in Educational Psychology, 2(1), 1-34.

Noels, K. A. (2003). Learning Spanish as a second language: Learners' orientations and perceptions of their teacher's communication style. In Z. Dörnyei (Ed.), Attitudes, orientations, and motivations in language learning (pp. 97-136). Oxford: Blackwell.

Oxford, R. L. (2013). Teaching and researching: Language learning strategies. NY: Routledge, Taylor \& Francis Group.

Pintrich, P. R., Smith, D. A., Garcia, T., \& McKeachie, W. J. (1991). A manual for the use of the motivated strategies for learning questionnaire (MSLQ). Ann Arbor: University of Michigan, School of Education.

Pintrich, P. R. (1999). The role of motivation in promoting and sustaining self-regulated learning. International Journal of Education, 31(6), 459-470.

Ryan, S. (2009). Self and identity in L2 motivation in Japan: The ideal L2 self and Japanese learners of English. In Z. Dörnyei, \& E. Ushioda, (Eds.), Motivation, language identity and the L2 self (pp. 120-144). Bristol: Multilingual Matters.

Schunk, D. H. (2009), Self-regulated learning. [Online] Available: http:/ /www.education.com/reference/article.htm (December 23, 2009)

Taguchi, T., Magid, M., \& Papi, M. (2009). The L2 motivational self system among Japanese, Chinese and Iranian learners of English: A comparative study. In Z. Dörnyei, \& E. Ushioda (Eds.), Motivation, language identity and the L2 self (pp. 66-97). Bristol: Multilingual Matters.

Ushioda, E. (2001). Language learning at university: Exploring the role of motivationalthinking. In Z. Dörnyei, \& R. Schmidt (eds.), Motivation and Second language acquisition (pp. 91-124). Honolulu, HI: University of Hawaii Press.

Zimmerman, B. J., \& Schunk, D. H. (Eds.) (2008). Motivation and self-regulated learning: Theory, research, and applications. Mahwah, $\mathrm{NJ}$ : Lawrence Erlbaum Associates.

Zimmerman, B. J., \& Schunk, D. H. (2011). Handbook of self-regulation of learning and performance. NY: Routledge. 